\title{
A Study of COVID-19 and Its Impact on Well Being of Society and Business
}

\author{
Amrita Sidhu ${ }^{1}$, Pretty Bhalla ${ }^{1} \&$ Inass Said Salamah $\mathrm{Ali}^{2}$ \\ ${ }^{1}$ Lovely Professional University, Phagwara, Punjab, India \\ ${ }^{2}$ MIS Department, Hekma School of Business \& Law, Jeddah, KSA \\ Correspondence: Inass Said Salamah Ali, MIS Department, Hekma School of Business \& Law, Jeddah, KSA.
}

Received: August 17, 2020

Accepted: November 5, 2020

Online Published: April 24, 2021

doi:10.5430/rwe.v12n3p7

URL: https://doi.org/10.5430/rwe.v12n3p7

\begin{abstract}
Pandemic is the worst situation faced by the world in every century. It not only leads to great human loss but unbearable economic loss also. In order to understand the nature \& severity of COVID- 19, emerged in the year 2019 in the Wuhan city of China we have studied the great pandemics occurred in 20th century i.e., influenza outbreak in 1918, 1957 and 1968 1918. The objective of this paper was to understand the severity, mitigating strategies and impact of COVID- 19 on the wellbeing of the society. A review research method was followed to collect the information regarding previous pandemic occurred and the prevailing situation of the society. It is being studied that, alike previous pandemics, this pandemic also leads to great human and economic losses all over the world. Transmission rate was so high that in few weeks it covers a large area under its impact. Similar mathematical model SIR (Susceptible- Infectious- Recovered) of transmission used in 20th century was used to understand the transmission process of COVID- 19. As far as mitigating strategies are concerned, it is being observed that similar strategies like travel restrictions, social distancing, home quarantine, school \& workplace closure which were used to control influenza pandemics were used to control the current situation. Recommendations were made on the basis of steps taken by the government in order to help the society.
\end{abstract}

Keywords: COVID-19, impact, measure, severity, wellbeing

\section{Introduction}

The term Pandemic is used for the wide spread of highly infectious disease over a large area such as continent or worldwide. As per WHO (World Health Organization) it is defined as "microbial agent that causes a pandemic must be a new one, never before found in human beings, and spread easily and comfortably among humans. In this paper we will discuss about some of the dangerous pandemics occurred in 20th \& 21st century. In the beginning of the 20th century, the pandemic influenza occurred at least thrice starting from 1918, 1957 and 1968. In the year 1918-19, pandemic named 'Spanish Flu' caused by swine flu variant Hemagglutinin Type 1 and Neuraminidase Type 1 (H1N1) subtypes of influenza viruses. This pandemic killed 550,000 people in USA and over 20-40 million over the world (Ghendon, 1994). The economic loss incurred by USA was approximately 167 million dollar (Tam, 1999). Another pandemic outbreak in 1957 was termed as 'Asian Flu' influenza virus A including Hemagglutinin and Neuraminidase (H2N2) and in the year 1967, it was 'Hong Kong Flu' (H3N2), which leads to 36,000 deaths alone in USA (Ghendon, 1994). 'Avian flu' outbreak in the year 2004 and many fatal human cases were reported from Thailand and Vietnam. This virus was originated from birds and mostly the rural people maintaining poultry flocks were at greater risk (Stöhr, 2005). In the year 2009, it was 'Swine Flu influenza' outbreak in Federal District of Mexico in the month of March. The cases steadily increased within few weeks and were reported in Canada \& USA. By April 2009 Mexico was having about 850 cases \& 60 deaths (Kerr, 2009). Similar type of virus disease outbreak in 2019 is termed as COVID-19, originated from Wuhan city of china and spread to many other countries of the world. It was declared as a global health emergency on 30th January, 2020 by World Health Organization (WHO) after watching its growing cases in China (Velavan and Meyer, 2020). The first five cases of COVI-19 were reported on 29th December, 2020 in China and as on 22nd, January, 2020 the number raise to 1975 along with 58 deaths (Tamblyn and Hinman, 1993). After 30th January, 2020 this virus extended over to the other countries like Taiwan, Vietnam, Malaysia, Nepal, India, Sri Lanka, United States of America, United Arab Emirates, The Philippines, Australia, Canada, Finland, Italy, France \& Germany (Rothana and Byrareddyb, 2020). This is the on-going 
pandemic which is adversely affecting the population as well as the economy of whole world due to its uncontrollable \& untreatable nature. This paper follows the research methodology given hereunder:

Mathematical formulation of methodology adopted for conducting the study:

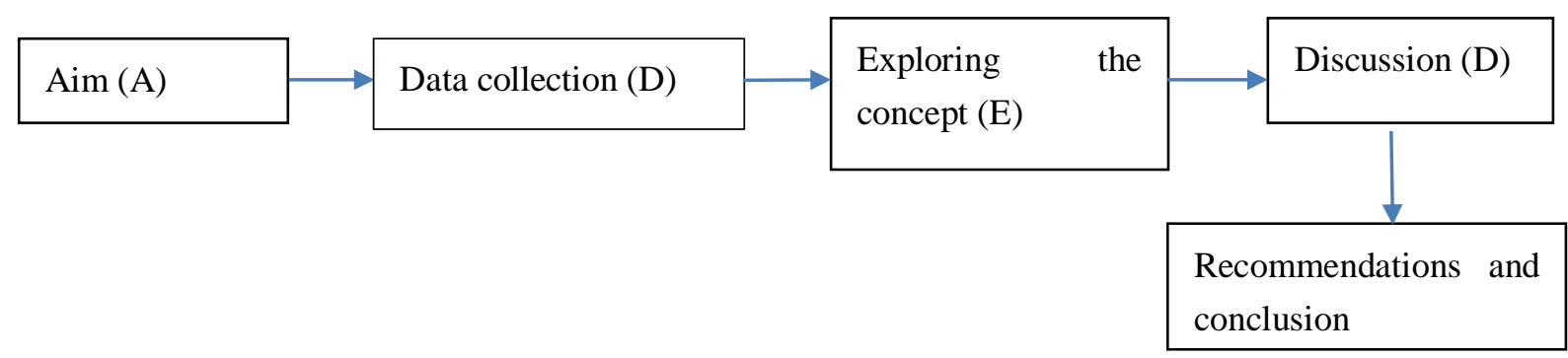

The research study conducted is qualitative in nature, therefore the main aim is:

To explore the severity and transmission of COVI-19 in light of previous pandemics.

To study the various mitigating strategies followed to control the transmission.

To study the impact of this pandemic on social wellbeing.

As per the aim of the research relevant literature was collected on the various parameters related to the study. Data collection consists of various statistical reports, articles and research papers published in context of COVID-19. Depth study of the collected information was done to explore the concept and drawing conclusions out of that. In the discussion part a general framework was made to depict the impact of Covid- 19 on Society Well Being based on the understanding of the researcher. Finally, the conclusion was drawn and recommendations were made to improve the present situation in future.

Now, let us discuss some of the clinical features of these pandemics.

\section{Clinical Features}

In comparison to other infectious diseases like plague or smallpox, influenza and coronaviruses spread more rapidly among the population and affect all the age groups (Aufderheide and Rodriguez, 1998). Influenza virus belong to the family of orthomyxo viridae and of three types of influenza A, influenza B and influenza C. Influenza A is mainly concerned with pandemics \& high mortality rate. Influenza B is similar to A as per its clinical presentation but it does not cause any pandemic \& is less severe, whereas, influenza $C$ does not lead to any influenza or epidemic but a mild infection in the upper respiratory tract among children \& adults (Hayden and Palese, 2002). Influenza A virus carries different combinations of viral envelope glycoprotein haemagglutin $(\mathrm{H})$ and neuraminidase $(\mathrm{N})$ which lead to which leads to influenza pandemic (Webster and Lim, 1992). On the other hand coronavirus was first mentioned by Tyrell \& Bynoc in the year 1966. As per them it is spherical in shape with a core shell named as coronaviruses, in latin corona means crown. There are 4 sub families of coronaviruses namely alpha, beta gama \& delta. Among these groups beta coronaviruses can infect human beings \& may cause severe diseases and deaths. Alpha and beta viruses were originated from mammals especially bats, whereas the other two gama \& delta originated from birds \& pigs. The SARS disease originated in the year 2003 belongs to the family of coronaviruses similar to COVID-19 (Velavan and Meyer, 2020). The evolution period of influenza A virus is from 1 to 5 days and symptoms starts with high fever, severe headache, chill and dry cough along with tightness in the chest (Burke and Cunha, 2004). Similarly, the symptoms of COVID- 19 start appearing after an incubation period of about 5.2 days (Rothana and Byrareddyb, 2020). It starts with common symptoms like fever, fatigue, cough, headache, diarrhoea, dyspnoea, lymphopenia and haemoptysis. Chest CT scan represents pneumonia along with abnormalities like acute cardiac injury, RN anaemia, acute respiratory distress syndrome and grand glass opacities in sub pleural regions of lungs (Huang, Wang, Ren, Zhao, Hu, et al., 2020). The illness caused by influenza gets resolved within 7 days (Van Voris, Young, Bernstein, Graham, Anderson, Gorse and Belshe, 1984). But as per the clinical manifestations of COVID-19, it leads to severe respiratory symptoms which damage the cardio vascular in patients and many patients already having cardio vascular disease as nearer to death. According to the Pneumonitis Diagnosis and Treatment program for new coronavirus infection (trail version 4) it was concluded that, among the patients having COVID- 19, 25\% suffering from heart disease, $58 \%$ from hypertension \& $44 \%$ from arrhythmia. The mortality data given by NHC shows $35 \%$ of patients 
died from this disease were having a history of hypertension and $17 \%$ were having a history of coronary heart disease. Moreover, its transmission rate is very high among human beings. Now, let us discuss some of the mathematical models related to the transmission of these deadly pandemics (Zheng, Ma, Zhang and Xie, 2020). The methodology adopted

\section{Mathematical Models \& Transmission}

The transmission rate of the pandemics is very high, in no time it spreads all over the world. Therefore, mathematical models were designed to know the transmission process of such pandemics. The basic model was developed by Kermack \&Mc Kendrick, named as SIR (Susceptible- Infectious- Recovered) model (Kermack and McKendrick, 1927). As per this model, the influenza infected individual (I) comes in contact with closed population where everyone is susceptible $(\mathrm{S})$, the probability of transmission is $\beta$. As the confirmed cases increases the epidemic will first reaches to its peak and then starts declining as infected individual recover and unable to transmit virus (Coburn, Wagner,and Blower, 2009). The severity of epidemic depends upon Ro (basic reproductive number), if Ro>1 then epidemic will occur and if Ro<1, the epidemic will stop or die. Similar model was applied to see the transmission process of COVI-19. As stochastic transmission model along with data related to COVID-19 in Wuhan \& outside Wuhan to know the transmission varied in Wuhan between December, 2019 and February, 2020. Model was divided into 4 parts: susceptible, exposed (not yet infectious), infectious \& removed (isolated, recovered, or no longer infectious). Rt was used as the mean number of secondary cases generated by a typical infectious individual on each day in a full susceptible population. As per the study, Rt declined from 2.35 to 1.05 after travel restrictions were applied (Kucharski, Russell, Diamond, Liu, Edmunds, Funk and Eggo, 2020). It means after applying the behavioural interventions like increasing social distancing, closing schools or avoiding crowds or imposing travel restriction can reduce the rate of transmission (Velavan and Meyer, 2020). The cases exported among 20 countries including USA and Australia, which were more connected to China were having more confirmed cases reported with a travel history to Wuhan and majority of them were symptomatic. Most of the infection was exported internationally from Wuhan in late January, 2020 (Kucharski, Russell, Diamond, Liu, Edmunds, Funk and Eggo, 2020). In order to control dangerous impact of such pandemics, the main concern of the government is to search for suitable \& effective mitigating strategies. Let us now discus some of the mitigating strategies followed earlier $\&$ now by the governments.

\section{Strategies for Mitigating the Pandemics}

After reviewing the literature, it was concluded the similar type of strategies were used to control the transmission rate of pandemics occurred in 20th century and recently outbreak COVID-19. In order to control the Influenza pandemic, the strategies like isolation, school or workplace closure, travel restrictions, home quarantine, antiviral \& vaccines were followed the Global Public Health department (Ferguson, Cummings, Fraser, Cajka, Cooley and Burke, 2006). Recently, the countries like China, Hong Kong \& Singapore control the pandemic by following such strategies. In China the value of Ro declined from 2.5 to below unity by following these measures (Anderson, Heesterbeek, Klinkenberg, and Hollingsworth, 2020). It is also being observed that social distancing is the most effective strategy to control such transmissions. During the influenza pandemic the border restrictions imposed by USA \& Great Britain delay the spread by 2 to 3 weeks only. School closure can reduce the peak attack rate of pandemic upto $40 \%$ applied at the time when pandemic is at the peak, but can't able to reduce the overall rates (Ferguson, Cummings, Fraser, Cajka, Cooley and Burke, 2006). It can reduce the transmission among children but it is not so helpful in controlling the disease (Anderson, Heesterbeek, Klinkenberg \& Hollingsworth, 2020). However, isolation or home quarantine can give good results in reducing the overall attack of the disease if followed under strict compliance (Ferguson, Cummings, Fraser, Cajka, Cooley and Burke, 2006). It is also being observed that individual behaviour is more important than government action in controlling the pandemic. In this context, the person having symptoms like dry cough, sore throat, \& fever can self-isolate themselves \& seek medical advice immediately before getting severe symptoms. Contact tracing is also considered to be an effective measure in reducing the pandemic. At least $70 \%$ of contacts are required to be traced to control the situation (Anderson, Heesterbeek, Klinkenberg \& Hollingsworth, 2020). These measures can control the situation up to a good mark before introduction of any vaccine in the market. Taking the recent pandemic i.e. COVID- 19 into consideration, it is being observed that, the drug used for treating SARS COV might be an option to treat COVID-19. The combinations of drugs like lopinavir and ritonavir were used to treat SARS COV patients and lead to improved conditions (Velavan and Meyer, 2020). The other options available are antiviral drugs like nucleoside analogces and HIV protease inhibitors (Rothana and Byrareddyb, 2020). Even choloroquine has the capacity to block viral infection by increasing endosonal ph required for fusing virus cell (Velavan and Meyer, 2020). The treatment given till date includes oral consumption of drugs like lopinavir $(500 \mathrm{mg})$, oseltamivir $(75 \mathrm{mg})$, ritonavir $(500 \mathrm{mg})$ and ganciclovir $(.25 \mathrm{~g})$ for 3 to 
14 days. Another report shows that broad spectrum antiviral remdsivir and choloroquine are considered to be highly effective in the treatment of COVID-19 (Rothana and Byrareddyb, 2020).

\section{Impact}

Pandemic give rise to many social \& economical problems all over the world. Along with the pain of high mortaliy among human beings the process or stratigies followed to control the disease are far more painful. Here, we can say that pandemics is a threat to the overall well being of the society. In this context some of the social psychologigst identified two types of threats termed as realistic threat \& symbolic threat, where former is related to attack on material \& physical well being (Sherif, 1966) while, later is related to attack on cultural \& national identity (Tajfel \& Turner, 1979). Disease brings in poor physical health as well as incresed unemployment further hampering the economic well being, which is directly related to realistic threat (Kachanoff \& Taylor, 2017). On the other hand,everyone in this society is mutually dependent upon each for motivation and psychological well being. The startegies like isolation, home quartine and social distancing negatively effects the wellbeing of the society and is related to symbolic threat (Maxouris, Almasy \& McLaughlin, 2020). Isolations is the most important step taken by the government to control the previous pandemics like influenza, SARS- CoV and recently for COVID-19 also, but it incresases the mental problems among people having prior psychological disorders (Fagan, Galea, Ahern, Bonner \& Vlahov, 2003). Now, let us indepandently discuss the various imacts of Covid-19 in light of social well being.

\subsection{Physical \& Psychological Impact}

In recent outbreak of COVID- 19, people are suffering both physcially \& mentally especially in terms of emotions \& cognition. After the decleration of COVID-19 people showed more negative emotions like anxiety, indignation \& depression (Li, Wang, Xue, Zhao, and Zhu, 2020). Lockdown \& social distancing has increased the anxiety, stress \& confusion among people by increasing their concerned about earnings, fear of job loss and timely availablity of essential supplies. Such stress and anger further lead to increased alcohol consumption \& domestic violence. In Jingzhou, a town near to Wuhan reported more than triple number of domestic voilence cases in February 2020, as compared to February 2019. Other than domestic voilence job loss is the major impact of COVID-19 further leading to stress, anxiety \& depression among people (Scott, 2020). As per McKinsey national consumer survey conducted from March 27, 2020 to March, 29, 2020, stated that the people whose job have been adversly affected by COVID-19 are more distress as compared to other people in US. Figure 1 depicts the reported signs of distress related to COVID-19 in US.

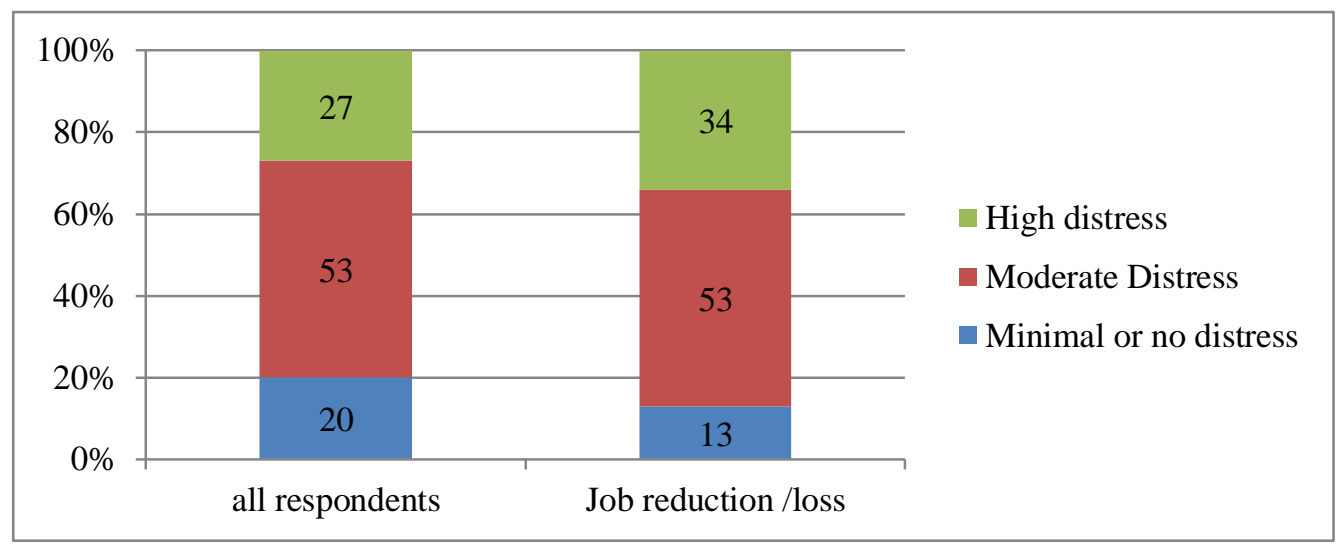

Figure 1. Reported signs of distress related to COVID-19 in US.

The total number of respondents were 1062 and out of them 319 were those whose job was under risk. In this context, chart 1 depicts that in both cases i.e all respondents \& people facing job loss, $27 \%$ \& $34 \%$ were under high distress, $53 \%$ (in both cases) were under moderate distress and $20 \%$ and $13 \%$ were under minimal or no distress. It means the people under minimal distress category were low as compared to high \& moderate distress (Coe and Enomoto, 2020). Similary in countries like turkey came out with spiritual, economic and biopsychosocial issues further leading to stress, anxiety, fear and behavioural issues among the individuals. In countries like Bangladesh, due to lack of knowledge about the pandemic leads to sucide of one individual suspecting himself Covid-19 positive. Due to fear of such mental issues, there are countries like Sweden who opted for no lockdown policy (Tanhan, Yavuz, Young, 
Nalbant, Arslan, Yıldırım, Ulusoy, Genç, Uğur, Çiçek, 2020).

Other than this, lack of information or circulation of wrong or fake informations on social media about COVID-19 also increases the panic among human beings further leading to anxiety \& stress (Scott, 2020). As per the sociodemographic data collected duing a study conducted in China revealed that females \& students sufferd a great psychological impact along with high level of anxiety, stress \& depression due to outbreak of COVID-19. Along with this the people suffering from physical symptoms of this disease and having a history of chronic illness with poor health staus are also under great psychological impact (Wang, Pan, Wan, Tan, Xu, Ho and Ho, 2020).

After the outbreak of COVID-19, the priorty of hospitals or medical staff is to attend the COVID-19 patients as compared to patients reaching hospitals for the treatment of other diseases. This delay in traetment of others deadly diseases is also becoming a major issue for the society. The closure of outpatient duties \& instructions of staying at home to control the pandemics is restricting the treatment of other diseases among people. As per study in USA, it is being observed that head \& neck cancer are doubling in volume within 1 to 3 months due to delay in diagnoses or treatment. The situations like rescheduling of appointments with oncologists, radiologist, lab assistants, pathologists and surgeons, lack of PPE kits, lack of ventilators (diverted towards treatment of COVID-19) and shifting healthcare workers towards COVID- 19 emergencey leads to delay in regular examination of patients suffering from head and neck cancer. Such delay in treatment leads to low level of survival rate among such patients (Werner, Carey, Albergotti, Lukens and Brody, 2020).

Impact of any pandemic is not just limited to the patients suffering from that disease but it also cover the people taking care of treating such patients for example, doctors, nurses or other health care wokrkers. During the outbreak of SARS-CoV in the year 200 the health care workers were also having psychiatric disordress after coping with comminity events. The emergency staff in Taiwan suffered from post-traumatic stress disorder (PTSD), due to interpersonal isolation and the fear that they will transmitt the disease to other people also (Lee, Kang, Cho, Kim \& Park, 2018). As per study conducted to trace the impact of COVID-19 on mental health, it is being observed that medical workers are dealing with situations like, overwork, frustration, isolation, discrimination, lack of contact with their family members and high risk of infection. These situations give rise to mental health isuues like anxiety, depression, insomnia, stress, anger \& fear among these workers (Torales, Higgins, Castaldelli-Maia and Ventriglio, 2020).

One of the study conducted in China stated that, starties like restricted travel plolicy shifted the interst of people towards their family and health instead to speding leisure time with friends. People started praying for the whole country through religion beliefs which relaxed their tense mood and generated positive emotions among them. It means somewhere there are positive impacts also in terms of getting social support from the family members \& reflecting group cohessiveness by parying for everyone rather than pure personal emotions. Along with this donation provided by people in terms of food and money to the people in need is also a sign of chohessivenss \& positivity ( Li, Wang, Xue, Zhao and Zhu, 2020).

\subsection{Economic Impact}

Outbreak of any infectieous disease give rise to many economic problems in the country. As per the conventional approch the information about mortality \& morbidity is used to estimate the future income loss faced by an economy. During the outbreak SARS epedemic in 2003 significant effects on economies were seen in terms of increased business operating cost, reduction in consumation of good \& servicies and increased risk premiums. Similarly during the influenza outbreak the total estimated economic cost beared by US economy was $\$ 73.1-\$ 166.5$ billion along with the GDP contarction of about $1.5 \%$ in the mild situation \& $5 \%$ in case of severe situation. Let us discuss the economic impact of COVID-19:

\subsubsection{Labour Supply}

Due to increase in mortality \& morbidity the supply of labour force is adversely effected. As per the study conducted in China, index of vulnerabity was used to measure the mortality rate, as per which counties who are more vunerable than China were having high mortality rate \& reverse in case of low vunerability. Absence of labour force from the work due to incubation period or taking care of the other family members lead to loss of productive capacity. In such a situation government concern is to control the mortality rate \& further spread of the disease, which lead to increase in government expenditure. A lot of expenditure is involved in the measures like health screening, increasing health facilities, strenghtening helathcare infrastucture \& preventing disease spread to other areas (McKibbin and Fernando, 2020) 


\subsubsection{Industrial Sector}

Lockdown is the another reason which is adversely affecting various industries like transportation, hospitality, shopping malls, restaurants and museums due to collpse of dicretionary spending by the consumer. The industries like coal firms, oil \& gas hit hard with negative returns on an average of $50 \%$ below start of the year price. Oil prices have incresed with decline in its consumption. The price of Brent oil lowered down from $\$ 68.90$ a barrel on 1 st January, 2020 to $\$ 50.5$ a barrel as on 28th February, 2020. Even the crude oil futures collasped by $\$ 20$ a barrel from January to February. China is having an improtant role in global ecomomy and COVID- 19 is negatively impacting its investment decisions and other countries which further lower oil prices. The risk attached to this diesease has forced the OPEC+ countries to further cut in oil production of 600,000 barrels a day taken as an emerygency measure already pledged at 1.7 million barrels a day (Arezki and Nguyen, 2020). Even the traditional sectors which are always stable recorded a downfall $20 \%$ or more. Other industries like, aerospace, banks, travel, media and hospitality declined by more than $30 \%$ (Hevia, and Neumeyer, 2020). It is being observed that the situation is more worse in hospitality industry due to reduction in activity by more than $90 \%$. Travel \& tourism holds $10 \%$ of the global GDP and due to its closure the job of 50 million people world wide are at risk (Scott, 2020). Due to travel restrictions, airlines are grounding their flights \& firing their staff members, hotel \& casions have closed their operations, trade fairs \& cruises are being cancelled and companies are cancelling foreign meeting $\&$ travelling. Such activities has landed the hospitality industry in a great crises. There are countries like Mexico, Spain, Greece or Portugal where tourism contributes 15\% in GDP are adversly affected by this crisis (Fernandes, 2020). Social distancing is increasing the cost of inputs over the gross production, as firms are still paying their wage bills, rents, taxes \& debts along with reduced or nil sale of good \& services (Hevia and Neumeyer, 2020).

\subsubsection{Supply Chain}

Supply chain is the another area which is under the negative impact of COVID-19. As per expected by World Trade Organiztion (WTO), the world trade will fall by $32 \%$ due this pandemic. Both the impoter \& expoter countries are bearing the losses due to lack of raw materials $\&$ final products. The companies like car manufacturing or watch manufacting are closing their operations due to lack of supply of components. There are companies like toy manufacturer Hasbro, which get $70 \%$ of its products from China is suffering a lot in this scenario (Fernandes, 2020). From past few decades China has become a critical supplier of inputs to various sectors like textile, Information \& technology, Car manufacturing, toys etc. all over the world. The Hubie province of China is known as the 'optic valley' as they manufacture fibre optic components which an essentinal input for telecom network. Due to outbreak of this pandemic the Hubie alone can knock $10 \%$ off worldwide shipment of smartphones. In case of automobile sector also China is a critial supplier of auto parts and the car manufacturing companies like Hyundai (Korea) \& Nissan (Japan) has closed their pant due to shortage of parts coming from China. Similarly, the gaint European manufacturers like Germany, the UK, France \& Italy are key suppliers to Europen nations. The supply disruptions will definitely effect the consumers \& firms existing in all major economies due to interdepandence of nations (Baldwin and Tomiura, 2020)

\subsubsection{Stock Market}

Stock market is the another area which is adversly affected by the outbreak of COVID- 19. The share price of many well known companies have fallen by more than $80 \%$ within few weeks. The stock market performnace of countries like UK and Germany is terribly marked as $-37 \%$ in case of UK and $-33 \%$ in case of Germany. The table 1 shows the top 10 negative performnaces on the graph of global stock markert for the year 2020:

Table 1. Global stock market performnace in 2020

\begin{tabular}{ll}
\hline Countries & Global stock market performnace \\
\hline Poland & -38 \\
\hline Belgium & -39 \\
\hline Thailand & -39 \\
\hline Russian & -40 \\
\hline South Africa & -40 \\
\hline Argentina & -40 \\
\hline
\end{tabular}




\begin{tabular}{ll}
\hline Austria & -41 \\
\hline Norway & -42 \\
\hline Greece & -44 \\
\hline Colombia & -47 \\
\hline Brazil & -48 \\
\hline
\end{tabular}

Source: Reuters Eikon

Table 1 has clearly depicted the 10 worst performers in global stock market, here bBrazil is low by $48 \%$ and Poland by $38 \%$. Similarly the others countries are down by $39 \%$ to $47 \%$ (Fernandes, 2020).

Impact of COVID- 19 is seen all over the world, in such a scenario the emerging economies are at greater risk in terms of reduced output, unemployment, labour loss \& declining GDP. Firstly, lockdown has reduced the output of each and every industry by restricting their operational activities. Secondly, to follow social distancing most of the people are working from home or do not work at all, which leads to decling in employee output as well as the organizational output. Thirdly, the counties who are exporting commodities to other countries are facing a sharp fall in price of the commodities they export which is negatively affecting their share of GDP and government revenues. Lastly, is the global financial shock beared by the emerging economies by large portfolio shift from riskier assests to safer liquid assets and further drop in the value of there curriencies (Hevia and Neumeyer, 2020).

\section{Government Intervention for the Well Being}

In response to the Covid-19 pandemic, every country has witnessed government intervention in order to mitigate the virus transmission. The six major interventions imposed by countries like China, Italy, India, Singapore, Spain, UK and US consists of centralize quarantine, lockdown, mask wearing, school closure, travel restrictions \& social distancing. These interventions were imposed in order to mitigate the Covid transmission all over the world. It was estimated that in China 180 million primary \& secondary students along with 47 million pre school children were confined at home and home schooling plan was efficiently administered during the lockdown. Huge efforts were made by schools and teachers to create an online study plan for delivering lectures to the students through TV broadcasts and internet. These efforts are helping parents to join their children with the education by avoiding study loss due to school closure (Wang, Zhang, Zhao, Zhang and Jiang, 2020). In order to tackle the psychological crisis emerged due to widespread to pandemic government introduced various psychological counselling helplines for public to address psychological issues faced by the individuals. In countries like China various medical institutions and universities started online platform to provide psychological counselling to patients, their family members and other individual affected by the pandemic (Duan and Zhu, 2020). In countries like turkey, to tackel with the spiritual, biopsychosocial and economic issues have created a social sciences board including experts to provide mental health support to the people. Phsical \& social isolation are considered to be the most harmful ways directly deteorating the immune system \& mental health of the individuals. It was observed that in turkey people approached Online Read Reflect Share (ORRS) bibliotherapy groups to get mental health services (Tanhan, Yavuz, Young, Nalbant, Arslan, Yıldırım, Ulusoy, Genç, Uğur , Çiçek, 2020). Along with psychological issues governments has made efficient interventions in order to stabalize the economy \& supporting businesses. In France, state gurantees on commercial loans \& credit line for the business enterprises up to 5000 employees. Direct grant given to the small \& micro enterprises (maximum 10 employees and annual turnover mot exceeding EUO 1 million) along with the self employed individuals affected by covid-19. In Germany also two subsidized loan schemes were introduced by German Bank Kreditarisnstalt fur Wiederaufbau (KfW) covering the risk up to $90 \%$ available to all companies (up to 5 year maturity and up to EUR 1 billion per company) $80 \%$ of the risk, but not more than $50 \%$ of a company's total debt, as part of a consortium of private banks. In this context the countries like Russia, have also introduced the schemes like "credit holiday", under which the small the medium sized enterprises working in the sectors which are higly affected by the pandemic may ask creditors to suspend their monthly payments and not to charge any interest against credit agreements. In UAE also the Central Bank and government allowed banks to tap AED 110 billion under TESS (Targeted Economic Support Scheme, thus allowing banks to boost up the lending and freeing up their reserves (McKenzie, 2020). There is a long list of interventions, but this paper has coverded few of them.

\section{Discussion}

Looking at the overll impact of Covid- 19 on well being, society is suffering from all the dimensions. Here we have created a framework where all the elements of well being are related to each other, impact of pandemic on one 
element will hurt the other element and so on.

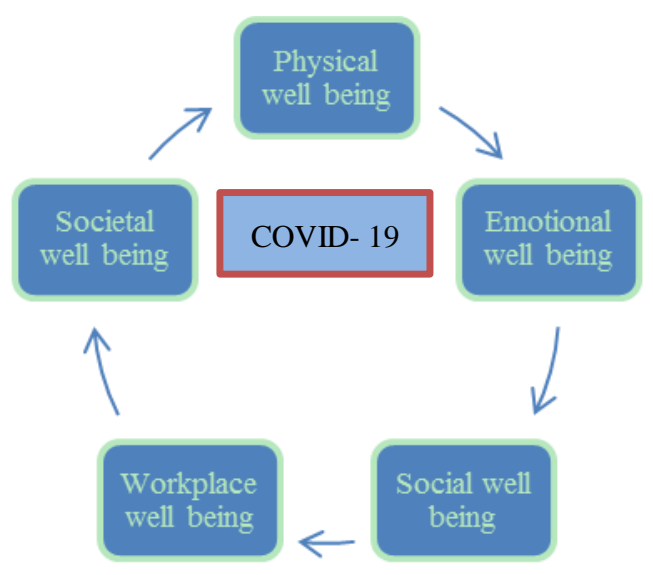

Figure 2. Impact of Covid- 19 on society well being

Figure 2 shows that physical well being is related to functioning of ones own body, in present scenarion people both the categories of people whether suffering from covid-19 or not suffeirng from this disease as facing physical health issues in terms of weakness, headache, respiratory problem etc. The people who are sitting at home due to pandemic are facing abdominal problems due to overeating or less eating. Physical health issues directly targets the emotional well being of an individual which is related to managing stress and feeling good. Poor physical health is a restriction towards managing stress an feeling good. As we have alrady disscued about the psychological impact of covid-19 on an individual. One's the person becomes emotionally weak, it further impacts the social wellbeing, which means, the ability of an individual to communicate, develop relationships and asking for support from others. Emotionally unstable person will feel lonlely and sometimes do not want to share his/her condition with others which further leads to the anxiety \& depression. Such a situation negatively impact the social well being of an individual. Due to lack of mobility under lackdown people are unable to communicate and meet their loved ones which makes them emotionally weak. This negative impact on social well being futher impact the workplace well being of an individual, which means gaining professional enrichment. When one is not communicating and shareing at a point of time the individual start loosing interest from his/ her professional activities which further leads to negative impact of workplace wellbeing. The absence of an individual from workplace and social activities leads to withdrawal from community and cultural events. Due to lackdown these activities are instructed to be avoided in order to control the transmission process of the pandemic. Long term avoidance and fear of tranamission negatively inpacts the societal well being of and individual. Therefore we can say that Covid-19 is creating impacting all the dimensions of well being related to an individual.

\section{Conclusion}

A pandemic is the worst situation for any country in this world not matter how well versed is that country in terms of medical services or technology. Its uncontrollable \& untreatable nature leads to huge human \& economical loss over the world. But it should be noted that strictly following some of the effective measure especially social distancing and reduce the transmission rate by a goo percentage in absence of any vaccination. Once the vaccination is out, it can be controlled upto $75 \%$ but the impact is always present psychological and economically. The impact of COVID-19 has covered each and every dimension of wellbeing in terms of psychological \& economic issues. It has changed the lives in terms of human thinking and financial equations. The life after this pandemic will be more challenging for each and every individual as well as for the world economy.

\section{Recommendations}

As per the study following recommendations are made:

We have discussed about the job loss people are facing due pandemic, in such a situation a portal pertaining to information about availability of job should be designed to help such people in getting new jobs.

Online study for kids is an appreciating effort made by government but some measures need to be taken for saving 
the young generation from mental \& physical stress arising out of such virtual classes. Over burden of work and long hours of classes needs to rechecked for smooth functioning of the system.

Due to Covid pandemic, hospitals and medical authorities are more diverted towards the treatment of Covid patients and giving less priority to the patients suffering from other harmful diseases. In such a scenario, it is recommended that every medical institute or hospital must design a separate helpline and Out Patient Duty (OPD) service for such patients who are suffering from separate diseases.

As far as psychological intervention is concerned, it is being observed that the team designed to impart online psychological help to the people under stress is not trained and is lack of professional experience in the field of psychology. It is recommended that a proper training must be given to the medical personnel in the particular field in order to achieve the required goal.

It is also being observed that the medical staff including doctors, nurses, ward boys who are handling the patients suffering from Covid- 19 are also dealing with the mental \& physical issues like fear of getting infected (own/family member), anxiety, long working hours, lack of rest and disturbed eating schedule. Therefore, it is recommended that, regular health check-ups and counselling sessions must be organized for such medical helpers to ensure their mental $\&$ physical safety.

\section{References}

Anderson, R. M., Heesterbeek, H., Klinkenberg, D., \& Hollingsworth, T. D. (2020). How will country-based mitigation measures influence the course of the COVID-19 epidemic?. The Lancet, 395(10228), 931-934. https://doi.org/10.1016/S0140-6736(20)30567-5

Arezki, R., \& Nguyen, H. (2020). Economics in the time of COVID-19. In R. B. Mauro, \& E. B. Mauro (Eds.), Novel coronavirus hurts the Middle East and North Africa through many channels (pp. 53-58). Centre for Economic Policy Research Press.

Aufderheide, A. C., \& Rodriguez, M. C. (1998). Influenza. The Cambridge Encyclopedia of Human Paleopathology, 210-212.

Baldwin, R., \& Tomiura, E. (2020). Thinking ahead about the trade impact of COVID-19. In R. A. Baldwin, \& E. B. Mauro (Eds.), Economics in the time of COVID-19 (pp. 59-71). Centre for Economic Policy Research Press.

Burke, A., \& Cunha, M. D. (2004). Influenza: historical aspects of epidemics and pandemics. Elsevier, 18, 141-155. https://doi.org/10.1016/S0891-5520(03)00095-3

Coburn, B. J., Wagner, B. G., \& Blower, S. (2009). Modeling influenza epidemics and pandemics: insights into the future of swine flu (H1N1). BMC Medicine, 1-8. https://doi.org/10.1186/1741-7015-7-30

Coe, E. H., \& Enomoto, K. (2020, April 2). Returning to resilience: The impact of COVID-19 on mental health and substance use. Mckinsey and Company.

Duan, L., \& Zhu, G. (2020). Psychological interventions for people affected by the COVID-19 epidemic. Department of Psychiatry. Shenyang: Lancet Psychiatry. https://doi.org/10.1016/S2215-0366(20)30073-0

Fagan, J., Galea, S., Ahern, J., Bonner, S., \& Vlahov, D. (2003). Relationship of self-reported asthma severity and urgent health care utilization to psychological sequelae of the September 11, 2001 terrorist attacks on the World Trade Center among New York City area residents. Psychosomatic Medicine, 65, 993-996. https://doi.org/10.1097/01.psy.000

Ferguson, N. M., Cummings, D. A. T., Fraser, C., Cajka, J. C., Cooley, P. C., \& Burke, D. S. (2006, July). Strategies for mitigating an influenza pandemic. Nature, 442. https://doi.org/10.1038/nature04795

Fernandes, N. (2020). Economic effects of coronavirus outbreak (COVID-19) on the world economy. European Corporate Governance Institute (ECGI), University of Navarra, IESE Business School. https://doi.org/10.2139/ssrn.3557504

Ghendon, Y. (1994). Introduction to pandemic influenza through history. European Journal of Epidemiology, 10, 451-453.

Hayden, F. G., \& Palese, P. (2002). Influenza virus in: Richman DD, Whitley RJ, Hayden FG (2nd ed.). Washington (DC): ASM Press.

Hevia, C., \& Neumeyer, A. (2020). A conceptual framework for analyzing the economic impact of COVID-19 and its policy implications March 2020. United Nations Development Programme, New York. 
Huang, C., Wang, Y., Li, X., Ren, L., Zhao, J., Hu, Y., et al.. (2020). Clinical features of patients infected with 2019 novel coronavirus in Wuhan, China. The Lancet, 395(10223), 497-506. https://doi.org/10.1016/S0140-6736(20)30183-5

Kachanoff, F. J., \& Taylor, D. M. (2017). Materialism: Rational and psychological perspectives. In The sage encyclopedia of political behavior. California: Thousand Oaks.

Kermack, W. O., \& McKendrick, A. G. (1927, August). A contribution to the mathematical theory of epidemics. Proceedings of the Royal Society A, 115, 700-721. https://doi.org/10.1098/rspa.1927.0118

Kerr, A. W. (2009). Political precaution, pandemics and protectionism. The Estey Centre Journal of International Law and Trade Policy, 10(2), 1-14.

Kucharski, A. J., Russell, T. W., Diamond, C., Liu, Y., Edmunds, J., Funk, S., \& Eggo, R. M. (2020). Early dynamics of transmission and control of COVID-19: a mathematical modelling study. Lancet Infectious Diseases. https://doi.org/10.1016/S1473-3099(20)30144-4

Lee, S. M., Kang, W. S., Cho, A.-R., Kim, T., \& Park, J. K. (2018). Psychological impact of the 2015 MERS outbreak on hospital workers and quarantined hemodialysis patients. Comprehensive Psychiatry, 87, 123-127. https://doi.org/10.1016/j.comppsych.2018.10.003

Li, S. J., Wang, Y. L., Xue, J., Zhao, N., \& Zhu, T. S. (2020). The impact of COVID-19 epidemic declaration on psychological consequences: A study on active Weibo users. International Journal of Environmental Research and Public health, 17(2032), 1-9. https://doi.org/10.3390/ijerph17062032

Maxouris, C., Almasy, S., \& McLaughlin, E. (2020). US coronavirus: For many Americans, a normal life is on hold-CNN. Retrieved from https://www.cnn.com/2020/03/12/health/coronavirus-us-updates-cases-thursday/index.html

McKenzie, B. (2020). COVID-19 government intervention schemes.

McKibbin, W., \& Fernando, R. (2020). The global macroeconomic impacts of COVID-19: seven scenarios. CAMA Working Paper 19/2020 February 2020, The Australian National University, Centre for Applied Macroeconomic Analysis- CAMA. https://doi.org/10.2139/ssrn.3547729

Rothana, H. A., \& Byrareddyb, S. N. (2020). The epidemiology and pathogenesis of coronavirus disease (COVID-19) outbreak. Journal of Autoimmunity, 109, 1-4. https://doi.org/10.1016/j.jaut.2020.102433

Scott, J. (2020, March 27). This is the human impact of COVID-19-and how business can help. The World Economic Forum.

Sherif, M. (1966). In common predicament: social psychology of intergroup conflict and cooperation.

Stöhr, K. (2005, January 27). Avian influenza and pandemics-research needs and opportunities. The New England Journal of Medicine, 405-407. https://doi.org/10.1056/NEJMe048344

Tajfel, H., \& Turner, J. C. (1979). An integrative theory of intergroup conflict. In W. G. Worchel (Ed.), The social psychology of intergroup relations (pp. 33-47). Monterey, CA: Brooks/Cole.

Tam, S. W. T. (1999). Preparing for influenza epidemics and pandemics in the New Millennium. Canadian Journal of Public Health, 90(5), 293-294. https://doi.org/10.1007/BF03404511

Tamblyn, S., \& Hinman, A. (1993). Pandemic planning: concluion concluion and recommendations. In C. Hannoun (Eds.), Options for the control of influenza II (pp. 457-459.). Amsterdam: Elsevier.

Tanhan, A., Yavuz, K. F., Young, J. S., Nalbant, A., Arslan, G., Yıldırım, M., ... Çiçek, İ. (2020). A proposed framework based on literature review of online contextual mental health services to enhance wellbeing and address psychopathology during COVID-19. Electronic Journal of General Medicine, 17(6), 1-11. https://doi.org/10.29333/ejgm/8316

Torales, J., Higgins, M. O., Castaldelli-Maia, J. M., \& Ventriglio, A. (2020). The outbreak of COVID-19 coronavirus and its impact on global mental health. International Journal of Social Psychiatry, 00(0), 1-4. https://doi.org/10.1177/0020764020915212

Van Voris, L. P., Young, J. F., Bernstein, J. M., Graham, W. C., Anderson, E. L., Gorse, G. J., ... Belshe, R. B. (1984). Influenza viruses. In R. B. Belshe (Ed.), Textbook of human virology (pp. 267-280). Littleton (MA): PSG Publishing Company. 
Velavan, T. P., Christian, G., \& Meyer, C. M. (2020). The COVID-19 epidemic. Tropical Medicine \& International Health, 25(3), 278-280. https://doi.org/10.1111\%2Ftmi.13383

Wang, C., Pan, R., Wan, X., Tan, Y., Xu, L., Ho, C. S., \& Ho, R. C. (2020). Immediate psychological responses and associated factors during the initial stage of the 2019 Coronavirus Disease (COVID-19) epidemic among the general population in China. International Journal of Environment Research and Public Health, 17(1729). https://doi.org/10.3390/ijerph17051729

Webster, G. R., \& Lim, L. W. (1992). A pandemic warning. Scientific Correspondence, 56, 152-179. https://doi.org/10.1128/MMBR.56.1.152-179.1992

Werner, M. T., Carey, R. M., Albergotti, W. G., Lukens, J. N., \& Brody, R. M. (2020). Impact of the COVID-19 pandemic on the management of head and neck malignancies. American Academy of Otolaryngology-Head and Neck Surgery Foundation, 1-2. https://doi.org/10.1177/0194599820921413

Zheng, Y. Y., Ma, T. Y., Zhang, Y. J., \& Xie, X. (2020). COID-19 and cardiovascular system. Nature Review. https://doi.org/10.1038/s41569-020-0360-5

\section{Copyrights}

Copyright for this article is retained by the author(s), with first publication rights granted to the journal.

This is an open-access article distributed under the terms and conditions of the Creative Commons Attribution license (http://creativecommons.org/licenses/by/4.0/). 